\title{
Assessment of reclamation status and identification of water stress using airborne remote sensing
}

\author{
M. Martínez de S. Álvarez ASL/Borstad Remote Sensing Inc., Victoria, BC \\ L. Brown ASL/Borstad Remote Sensing Inc., Victoria, BC \\ G. Borstad ASL/Borstad Remote Sensing Inc., Victoria, BC \\ P. Martell Highland Valley Copper, Logan Lake, BC \\ J. Dickson Highland Valley Copper, Logan Lake, BC \\ M. Freberg Highland Valley Copper, Logan Lake, BC
}

\begin{abstract}
Airborne remote sensing has been used at Highland Valley Copper since 2001 as part of the reclamation program to provide annual high spatial resolution maps of vegetation cover. These maps cover the entire mine site and complement the vegetative assessments. This unique and growing dataset allows us to examine vegetation changes over time with spatial resolution of about $3 \mathrm{~m}$. We can now classify the entire mine site according to its vegetation history and whether or not it has reached and maintained biomass above 1500 $\mathrm{kg} / \mathrm{ha}$, which is the permit threshold for self-sustaining status. The resulting 'reclamation status maps' provide a detailed synopsis of the vegetation trends between 2001-2010. They are designed to be helpful to reclamation managers and provide a means to focus further remediation effort on specific locations most needing it, rather than having to make wholesale changes to entire sites.
\end{abstract}

An analysis of the 10-year time series has revealed statistically significant correlations between the temporal patterns of remotely sensed vegetation cover and precipitation across much of the Highland Valley site. The strength and time scale of these correlations are related to the water retention capability of each location, which in turn is related to slope and material. These factors vary spatially across the mine site. Maps of these precipitation vs. vegetation correlations offer great potential value for reclamation management, because they identify the particular locations most likely to benefit from more rigorous soil remediation measures such as the addition of wood chips, biosolids, or trenching and mounding.

In this presentation we demonstrate how a comparison of time series reclamation coverage maps with precipitation response maps can aid in the identification of areas where growth is limited by excessively dry conditions, which can then be targeted for specific interventions thus improving the likelihood of successful reclamation.

Keywords: Highland Valley Copper, reclamation, vegetation, change, remote sensing, precipitation, water retention

\section{Introduction}

Highland Valley Copper (HVC) is the largest open pit copper mine in Canada, situated between 1200 and $1600 \mathrm{~m}$ above sea level on the Thompson Plateau, near the town of Logan Lake in British Columbia and 75 km southwest of Kamloops. HVC originated from the merging of four mining operations: Lornex, Valley, Bethlehem and Highmont. Operations at the latter two were discontinued in the mid-1980s, and decommissioning begun. With the discovery of new ore bodies, production is now planned to extend into 2025, with expansion at Lornex, Valley and Highmont. By the end of the mine's life, a total of almost 6,300 ha will have been disturbed, the majority of which will be reclaimed (Richards et al., 2004).

Reclamation is an integral part of production and decommissioning at HVC, and both in situ conventional and aerial remote sensing monitoring programs are being conducted annually to assess the progress toward achieving the end land use objectives, and to determine when individual sites achieve a self-sustaining state. 
The remote sensing program provides continuous maps of the vegetative changes over time for the entire mine site, which supplement the more detailed but less synoptic ground biological surveys and provide a means to focus further remediation efforts on specific locations most needing it, rather than having to make wholesale changes to entire sites (Richards et al., 2003, 2004; Borstad et al., 2005, 2009).

\section{$2 \quad$ Methods}

\subsection{Airborne Data}

Aerial multispectral surveys over revegetated areas have been acquired every year between 2001 and 2010, except for 2004. The multispectral airborne image data were acquired using a Compact Airborne Spectrographic Imager (CASI) configured to acquire imagery in 9 spectral bands at $2.5 \mathrm{~m}$ spatial resolution. The imagery was radiometrically calibrated, geometrically and geographically corrected to a digital orthophoto provided by the mine in order to produce image mosaics for target areas specified by HVC. All radiance mosaics were mapped to coordinates consistent with the mine Geographic Information System (Mine Units), with an estimated geographic accuracy of $\pm 10 \mathrm{~m}$ (Richards et al., 2003; Borstad et al., 2005).

\subsection{Vegetation Indices and Remote Sensing Biomass (RSB)}

The Normalized Difference Vegetation Index (NDVI), computed as the ratio of the measured intensities in the red $(665 \mathrm{~nm})$ and near infrared $(776 \mathrm{~nm})$ spectral bands, is commonly used in remote sensing to quantitatively measure vegetation cover (Tucker, 1979, Jackson et al., 1983, Tucker et al., 1991). The principle behind NDVI is that chlorophyll causes considerable absorption of incoming sunlight at $665 \mathrm{~nm}$ in the red region of the electromagnetic spectrum, whereas a plant's spongy mesophyll leaf structure creates considerable reflectance at $776 \mathrm{~nm}$ in the near infrared region of the spectrum. NDVI is generally proportional to the biomass of healthy green vegetation, but tends to underestimate biomass where the vegetation has lost chlorophyll due to desiccation. For application to Highland Valley we have calibrated NDVI to 'remote sensing biomass' (RSB) based on a comparison of CASI and in situ observations from 2001 to 2003 (Borstad Associates, 2006).

\subsection{Temporal classification}

In order to produce qualitative maps of the changes of vegetation cover over time, the annual NDVI maps were classified using an unsupervised algorithm (ISODATA in ENVI 4.2 ${ }^{\mathrm{TM}}$ ) normally used to classify multispectral data. Used in this way, pixels with similar NDVI trends were grouped into provisional temporal classes. These classes were then grouped manually into 11 final reclamation status classes (Table 1) according to the observed trends in RSB, and whether or not by 2010 they had reached a biomass above $1500 \mathrm{~kg} / \mathrm{ha}$, the accepted reclamation threshold (Jones \& Associates, 2005). Additional information on vegetation composition and degree of desiccation was obtained from site visits and photographs. The classification algorithm was applied to each mosaicked area on an individual basis because of the complexity of the temporal information and the unique characteristics of each area. However, the final 11-class groupings are the same for all areas.

\subsection{Precipitation response}

The sensitivity of restored vegetation to desiccation was evaluated by examining the time scales of NDVI response to precipitation. Areas with drought-tolerant vegetation and/or soils with good water retention could be expected to show growth responses over the longest time scales, whereas those with sensitive vegetation and poor water retention would show the shortest responses to precipitation.

Precipitation records from the Environment Canada Lornex weather station were summed for the 10, 20, 30 or 60 days prior to each annual CASI data acquisition flight between 2001 and 2010. Linear correlations were computed on a pixel-by-pixel basis for the relationship between cumulative precipitation and NDVI, and maps were generated showing the time scale of the strongest relationship in each case. In order to avoid errors in the correlations due to manmade disturbances, pixels with an NDVI value of 0 or less (no vegetation) at any time in the data record were excluded from analysis. This rather crude filter did not, 
however, remove areas subjected to fertilization treatments, or those disturbed long enough before the annual CASI flight for vegetation to have begun to re-grow. More work can improve the maps.

Table 1 Descriptions of the 11 reclamation status classes generated by the temporal classification

\begin{tabular}{|c|c|c|c|c|}
\hline \multirow[b]{2}{*}{ 2001- 2010 Trend } & \multicolumn{3}{|c|}{$\begin{array}{l}\text { 2010 RS biomass } \\
\text { (kg/ha) and Class }\end{array}$} & \multirow[b]{2}{*}{ Description } \\
\hline & $>1500$ & $<1500$ & $<750$ & \\
\hline Stable or weakly varying & 1 & 5 & 9 & $\begin{array}{l}\text { (1) good areas: dense green vegetation } \\
\text { (5) moderate areas: green /dry/ sparse } \\
\text { vegetation } \\
\text { (9) limited areas: poorly vegetated areas, not } \\
\text { establishing }\end{array}$ \\
\hline $\begin{array}{l}\text { Rapid growth since } 2001 \\
\text { or } 2002\end{array}$ & 2 & 6 & & $\begin{array}{l}\text { (2) new / limited /moderate areas, established by } \\
2010 \\
\text { (6) not yet established by } 2010\end{array}$ \\
\hline Rapid decrease & 3 & 7 & & $\begin{array}{l}\text { (3) areas experiencing a rapid loss of RSB, but } \\
\text { still }>1500 \mathrm{~kg} / \mathrm{ha} \text { in } 2010 \\
\text { (7) loss leading to RSB }<1500 \mathrm{~kg} / \mathrm{ha} \text { in } 2010\end{array}$ \\
\hline $\begin{array}{l}\text { Very variable, strongly } \\
\text { affected by desiccation }\end{array}$ & 4 & 8 & & $\begin{array}{l}\text { (4) dense grass areas } \\
\text { (8) moderate grass areas }\end{array}$ \\
\hline $\begin{array}{l}\text { Disturbed after } 2005 \text { and } \\
\text { recovered by } 2010\end{array}$ & 10 & & & $\begin{array}{l}\text { good / moderate areas that were disturbed after } \\
2005 \text { and had RSB }>1500 \mathrm{~kg} / \mathrm{ha} \text { by } 2010\end{array}$ \\
\hline $\begin{array}{l}\text { Disturbed after } 2005 \text {, and } \\
\text { not recovered by } 2010\end{array}$ & & 11 & & $\begin{array}{l}\text { good / moderate areas that were disturbed after } \\
2005 \text { and had RSB }<1500 \mathrm{~kg} / \mathrm{ha} \text { in } 2010 \\
\text { areas that suffered vegetation loss not caused by } \\
\text { mine activities }\end{array}$ \\
\hline
\end{tabular}

\section{$3 \quad$ Results}

\subsection{Reclamation Status Maps}

Figure 1 illustrates the 2010 reclamation status for the four major reclamation areas. The 11 classes listed in Table 1 have been merged to show only the 2010 RS biomass, whether successfully reclaimed ( $>1500 \mathrm{~kg} / \mathrm{ha}$, classes 1-4, 10), not yet established $(750-1500 \mathrm{hg} / \mathrm{ka}$, classes $5,6,8)$, or limited $(<750 \mathrm{~kg} / \mathrm{ha}$, classes 7,9 , 11). The maps demonstrate that on average, more than $50 \%$ and up to $79 \%$ of the areas had been successfully reclaimed as of 2010. The areas requiring most attention (largest 'limited/loss' class, black in Figure 1) tend to be along pond margins (where naturally fluctuating water levels will have an effect) and at specific sites such as Heustis in area A6.

Table 2 gives the full classification breakdown, showing not only the current reclamation status but the tenyear trends at each site. Looking at the 750-1500 kg/ha classes ('not yet established'), this more detailed analysis shows that some of these areas ('rapid growth' class 6) are on track to reclamation success if the current growth trend continues, while others will likely require intervention (class 7, 'rapid decrease').

The analysis also shows that a large fraction of the area rated 'successfully reclaimed' is subject to desiccation. The interpretation of this class is that although the biomass is generally good, the remote sensing data shows strong year-to-year variability in vegetation greenness. Measures to improve water retention in these areas may be beneficial. 

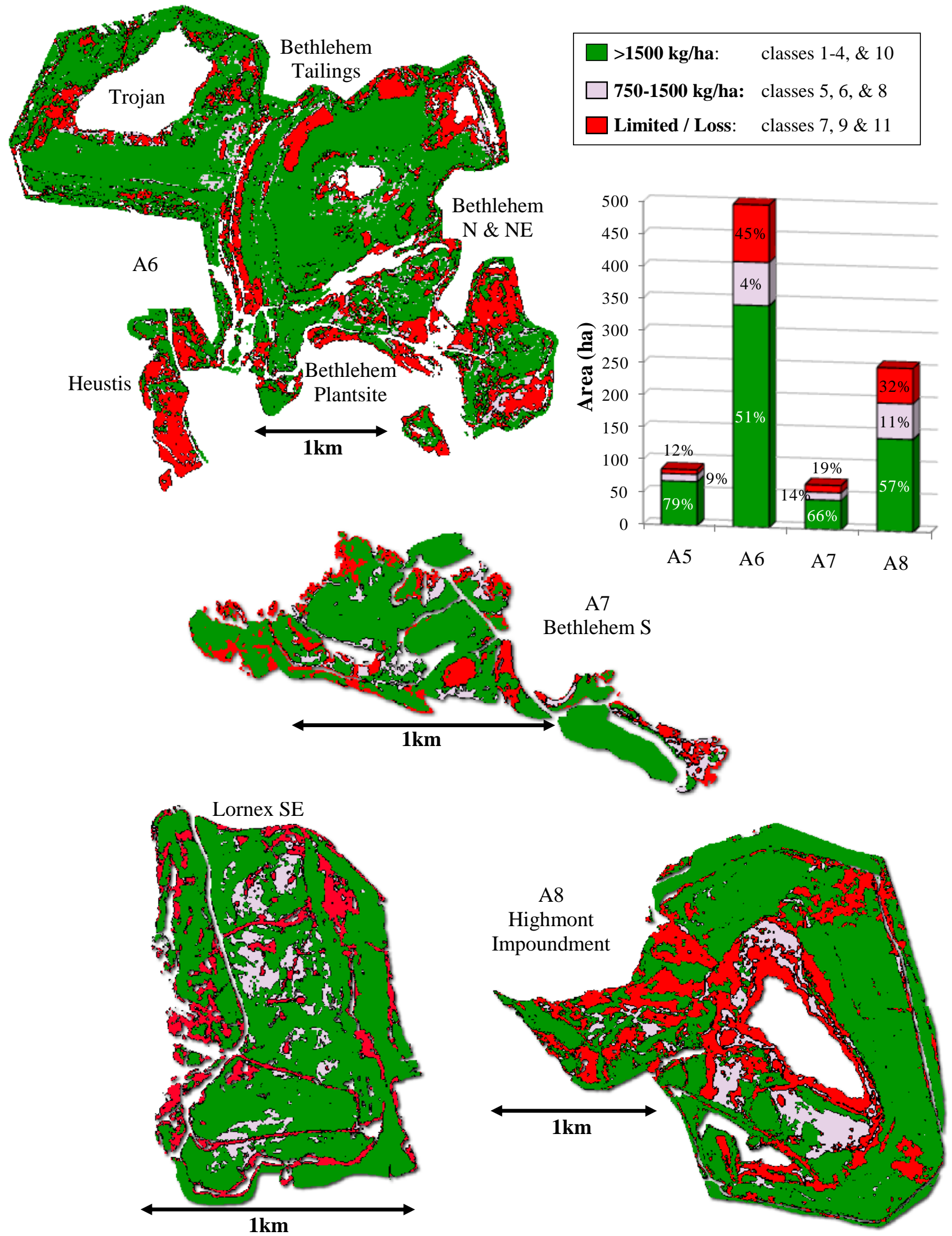

Figure 12010 reclamation status maps for the 4 major mining areas at Highland Valley Copper, showing remote sensing biomass estimates for 2010. Note that scales vary 
Table 2 Summary of 2001-2010 temporal classifications at the 4 Highland Valley mining areas

\begin{tabular}{|c|c|c|c|c|c|c|c|c|c|c|c|c|c|c|}
\hline 2010 RSB & \multicolumn{6}{|c|}{$\begin{array}{c}>1500 \mathrm{~kg} / \mathrm{ha} \\
\text { (successfully reclaimed) }\end{array}$} & \multicolumn{5}{|c|}{$\begin{array}{c}750-1500 \mathrm{~kg} / \mathrm{ha} \\
\text { (not yet established) }\end{array}$} & \multicolumn{3}{|c|}{$\begin{array}{c}750 \mathrm{~kg} / \mathrm{ha} \\
\text { (limited/loss) }\end{array}$} \\
\hline \multirow[t]{2}{*}{ Class } & 1 & 2 & 3 & 4 & 10 & & 5 & 6 & 7 & 8 & & 9 & 11 & \\
\hline & \begin{tabular}{l}
$\frac{0}{\pi}$ \\
$\frac{\pi}{5}$ \\
\multirow{2}{*}{}
\end{tabular} & 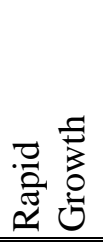 & 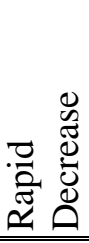 & 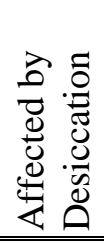 & 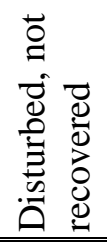 & 胥 & $\begin{array}{l}\frac{0}{\pi} \\
\frac{\pi}{\tilde{N}}\end{array}$ & 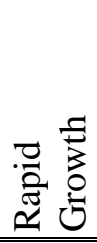 & 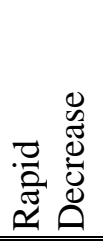 & 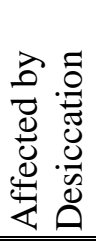 & 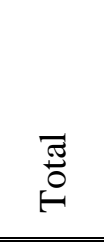 & $\begin{array}{l}\frac{0}{\pi} \\
\frac{\pi}{\tilde{n}} \\
\end{array}$ & 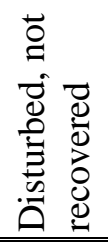 & 氶 \\
\hline \multicolumn{15}{|c|}{ Lornex SE (area A5) } \\
\hline $\mathrm{Ha}$ & 18.6 & 2.1 & 3.3 & 43.8 & - & 68 & - & 2.8 & 3.3 & 5.3 & 11 & 4.8 & 2.1 & 7 \\
\hline$\%$ Area & $22 \%$ & $2 \%$ & $4 \%$ & $51 \%$ & - & $79 \%$ & - & $3 \%$ & $4 \%$ & $6 \%$ & $13 \%$ & $6 \%$ & $2 \%$ & $8 \%$ \\
\hline Avg RSB & & & & & & 2988 & & & & & 907 & & & 212 \\
\hline \multicolumn{15}{|c|}{ Bethlehem Tailings, Trojan, Heustis (area A6) } \\
\hline $\mathrm{Ha}$ & 83.7 & 57.2 & 5.3 & 151.8 & 45.9 & 344 & 0.0 & 11.6 & 37.4 & 18.2 & 67 & 205.8 & 63.2 & 269 \\
\hline$\%$ Area & $12 \%$ & $8 \%$ & $1 \%$ & $22 \%$ & $7 \%$ & $51 \%$ & $0 \%$ & $2 \%$ & $5 \%$ & $3 \%$ & $10 \%$ & $30 \%$ & $9 \%$ & $40 \%$ \\
\hline Avg RSB & & & & & & 3299 & & & & & 1064 & & & 375 \\
\hline \multicolumn{15}{|c|}{ Bethlehem S (area A7) } \\
\hline $\mathrm{Ha}$ & 0.0 & 23.7 & 0.0 & 12.5 & 9.4 & 46 & 0.0 & 5.7 & 1.9 & 4.2 & 12 & 9.2 & 2.0 & 11 \\
\hline$\%$ Area & $0 \%$ & $34 \%$ & $0 \%$ & $18 \%$ & $14 \%$ & $66 \%$ & $0 \%$ & $8 \%$ & $3 \%$ & $6 \%$ & $17 \%$ & $13 \%$ & $3 \%$ & $16 \%$ \\
\hline Avg RSB & & & & & & 3227 & & & & & 794 & & & 604 \\
\hline \multicolumn{15}{|c|}{ Highmont Impoundment (area A8) } \\
\hline $\mathrm{Ha}$ & 19.9 & 32.0 & 14.1 & 24.2 & 53.3 & 143 & 12.2 & 7.8 & 27.5 & 7.7 & 55 & 41.2 & 13.6 & 55 \\
\hline$\%$ Area & $8 \%$ & $13 \%$ & $6 \%$ & $10 \%$ & $21 \%$ & $57 \%$ & $5 \%$ & $3 \%$ & $11 \%$ & $3 \%$ & $22 \%$ & $16 \%$ & $5 \%$ & $22 \%$ \\
\hline Avg RSB & & & & & & 3037 & & & & & 978 & & & 549 \\
\hline \multicolumn{15}{|l|}{ All areas } \\
\hline $\mathrm{Ha}$ & 122 & 115 & 23 & 232 & 100 & 601 & 12 & 28 & 70 & 35 & 145 & 261 & 81 & 342 \\
\hline$\%$ Area & $11 \%$ & $11 \%$ & $2 \%$ & $21 \%$ & $10 \%$ & $55 \%$ & $1 \%$ & $3 \%$ & $6 \%$ & $3 \%$ & $13 \%$ & $24 \%$ & $7 \%$ & $31 \%$ \\
\hline
\end{tabular}

RSB: remotely sensed biomass (kg/ha)

\subsection{Temporal trends}

Figure 2 shows a map of the temporal trends at Highmont Impoundment (area A8), created by merging the 11 classes from Table 1 according to the ten-year trends in NDVI, whether stable (classes 1, 5, 9), increasing (classes 2, 6, 10), decreasing (classes 3, 7, 11), or variable and subject to desiccation (classes 4, 8). 
Highmont is a large and complex site, and in 2010 the vegetation was at several different stages of reclamation. Large areas to the north and west that were disturbed in 2008 were showing good recovery in 2010 (white areas labelled 'A' in Figure 2). Of concern are three areas (black, labelled 'B') that were in

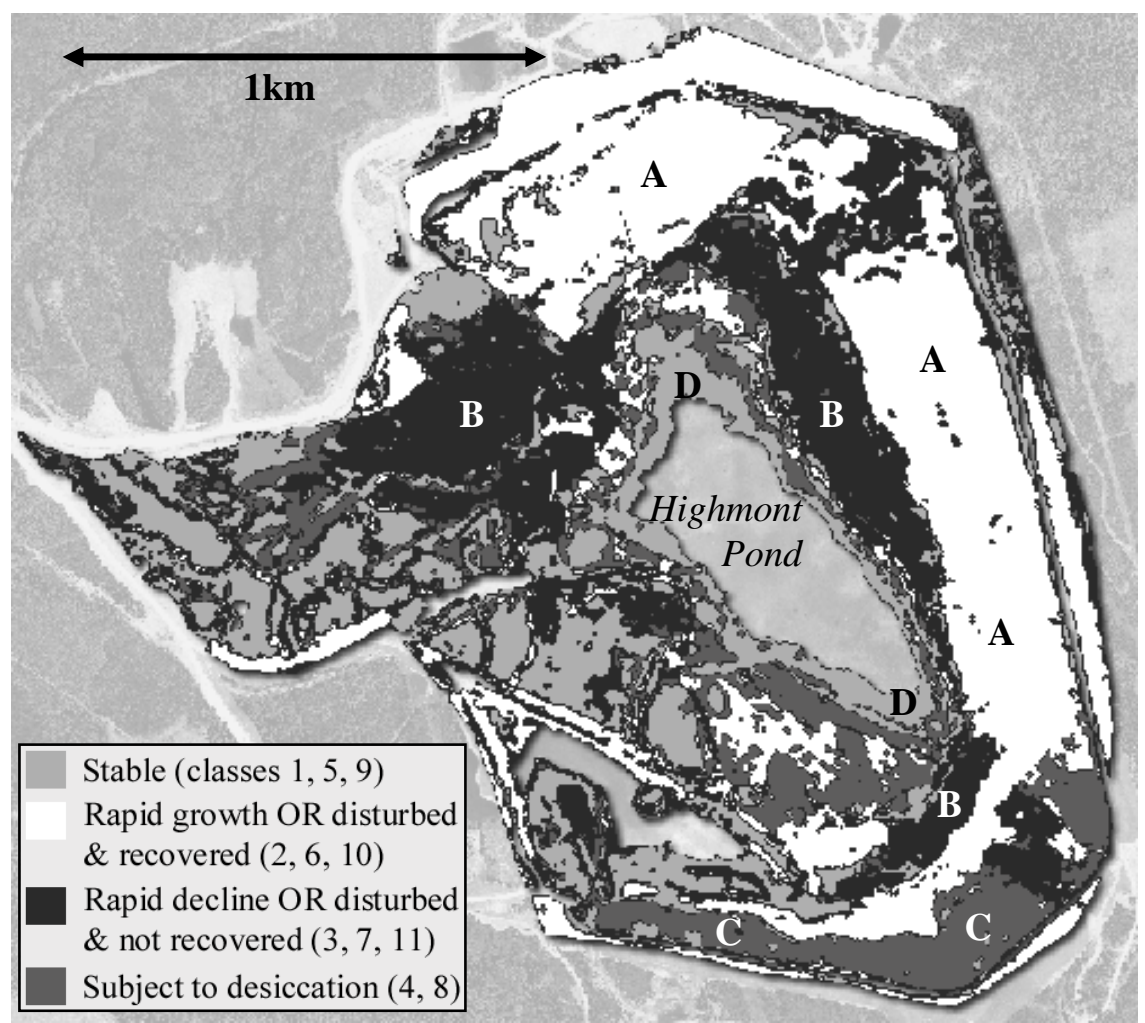

Figure 2 Summary of 2001-2010 reclamation trends at Highmont Impoundment. The background image is the 2010 digital orthophoto, shown here to provide context

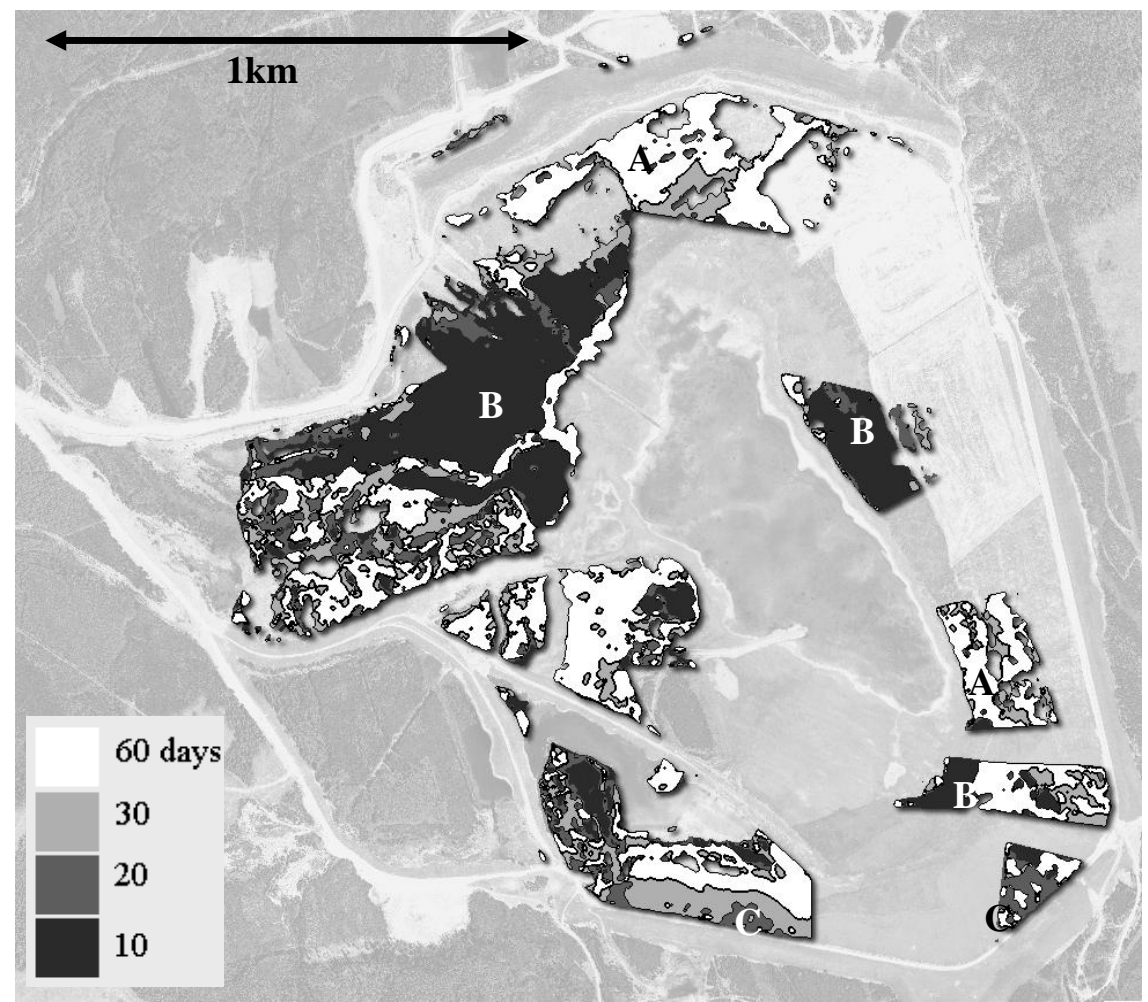

Figure 3 Time scales of NDVI response to precipitation at Highmont Impoundment, shown with the 2010 digital orthophoto to provide context 
decline and will likely require intervention if they are to achieve (or maintain) reclamation status. These mostly legume areas may be responding to availability of moisture. Water levels in Highmont Pond have decreased by almost $80 \mathrm{~cm}$ since 2003 . To the south is a large area subject to desiccation (dark grey, ' $\mathrm{C}$ '). The vegetation here is primarily grass that is known to bleach under drought conditions. The margins of Highmont Pond (D) are shown to be stable; however, Figure 1 shows that the RS biomass is low. This area in fact undergoes periodic inundation as the water level in the pond changes from year to year, and the vegetation consists of aquatic species which are underrepresented by the NDVI index when submerged. An aquatic vegetation program forms part of the overall Highland Valley reclamation plan.

\subsection{Precipitation response}

Figure 3 shows the results of the precipitation response analysis for Highmont Impoundment. A large proportion of this site was excluded from the analysis due to disturbances over the course of the ten-year time series, however the analysis does provide some insight into the areas identified as in decline from the temporal classification (' $\mathrm{B}$ ' in Figure 2). While areas performing well ('A') were able to use precipitation accumulated up to 60 days prior to the imaging date (white in Figure 3), the areas in decline were responding to precipitation occurring only within 10 days of imaging (' $\mathrm{B}$ ' in both figures). This suggests that intervention to improve substrate water retention, and/or a switch to more drought tolerant species, could improve vegetation growth in these areas. The analysis also shows that areas identified as variable and subject to desiccation from the temporal analysis (' $C$ ') were generally able to use precipitation accumulated within 20 to 30 days. The fact that their biomass was good (Figure 1) suggests that this was adequate to sustain growth, but measures to improve water retention could result in better overall vigour.

Although not shown here, a 3-dimensional drape of the precipitation response maps over a digital elevation model can be informative. Using Google Earth ${ }^{\mathrm{TM}}$ overlays, we found strong relationships between precipitation response and slope, as well as substrate composition and exposure.

\section{$4 \quad$ Conclusions}

The ten-year time series of airborne imagery at Highland Valley Copper has permitted a variety of analyses that are being used in the management of the reclamation program. The NDVI remote sensing index provides a synoptic snapshot of the vegetation over entire mine site that can be used to assess its condition at one point in time. The remote sensing image data can be transformed into maps of biomass and reclamation status relative to target thresholds, using in situ data to calibrate NDVI to vegetation biomass.

As the HVC aerial surveys have been repeated over time, the trends in NDVI and inferred biomass have demonstrated the trajectory of the reclamation at each site, and more importantly, clearly delimited the extents of areas performing well under the planned program, as well as those requiring additional intervention. A comparison of NDVI and precipitation over time provides a third valuable management tool that allows exploration of the underlying relationships between vegetation and water, and pinpointing areas where increased water retention measures, such as the addition of wood chips, biosolids, or trenching and mounding, would be beneficial.

One aspect of the NDVI index is its sensitivity to vegetation greenness as well as biomass. The HVC time series has revealed areas, generally dominated by grasses, where greenness varies widely with variations in precipitation, with only moderate changes in biomass. The temporal classification has enabled us to separate these areas from those undergoing steady increases or decreases. More recently we have begun an examination of the residuals to the NDVI-precipitation relationship, which may also help to resolve these effects on a year-by-year basis.

The strength of remote sensing is the consistent, synoptic view it is able to provide of a mine reclamation program and its progress over time. The high spatial resolution and flexibility of spectral configuration and acquisition timing characteristic of airborne systems make them ideal for this application, but satellites have seen recent improvements in spatial resolution in particular that make them a less expensive alternative. However, the reduction in cost comes at increased risk, since satellite surveys are more affected by cloud than those from aircraft that can be operated under cloud. What is also attractive about satellite data is that archives now exist for some sensors (especially lower resolution ones) that permit retrospective analysis such as that presented here. 


\section{Acknowledgements}

We thank Randy C. Kerr, José Lim and Peter Willis, members of the ASL/Borstad remote sensing group, for their valuable contributions during data acquisition, pre-processing, and geo-rectification.

\section{References}

Borstad Associates Ltd. (2006) Multispectral mapping of reclaimed areas: extended analysis of the 2005 imagery. Highland Valley Copper 2005 Annual Reclamation Report vol II report 8.

Borstad, G. A., Brown, L., Martínez, M., Hamaguchi, B., Dickson, J. and Freberg, M. (2009) Airborne mapping of vegetation changes in reclaimed areas at Highland Valley between 2001 and 2008 . Presented at the $33^{\text {rd }}$ British Columbia Mine Reclamation Symposium, Cranbrook, BC, 14-17 September 2009, 10 p.

Borstad, G. A., Martínez, M., Larratt, H., Richards, M., Brown, L., Kerr, R. and Willis, P. (2005) Using multispectral remote sensing to monitor aquatic vegetation in ponds at a reclaimed mine site. Presented at the $29^{\text {th }}$ British Columbia Mine Reclamation Symposium, Abbotsford, BC, 19-22 September 2005, 11 p.

Jackson, R.D., Slater, P.N., and Pinter, P.J. (1983) Discrimination of growth and water stress in wheat by various vegetation indices through clear and turbid atmospheres. Remote Sensing of the Environment, v. 15, p.187-208.

Jones \& Associates Ltd. 2005. Reclamation Permit No. M-11, Volume 1. Unpublished report prepared for Highland Valley Copper by C. E. Jones \& Associates Ltd., Victoria. 86 p.

Richards, M., Borstad, G. A. and Martínez de Saavedra Álvarez, M. (2004) Using multispectral remote sensing to monitor reclamation at Highland Valley Copper. Presented at the $28^{\text {th }}$ British Columbia Mine Reclamation Symposium, Cranbrook, BC, 21-24 June 2004, 15 p.

Richards, M., Martínez de Saavedra Álvarez, M. and Borstad, G. A. (2003) The use of multispectral remote sensing to map reclaimed areas at Highland Valley Copper. Presented at the $105^{\text {th }}$ CIM Annual General Meeting, Montreal, QC, May 2003, 9 p.

Tucker, C.J. (1979) Red and photographic infrared linear combinations for monitoring vegetation. Remote Sensing of the Environment, v. 8, p.127-150.

Tucker, C. J., Newcomb, W. W., Los, S. O., and Prince, S. D. (1991) Mean and inter-year variation of growing-season normalized difference vegetation index for the Sahel 1981-1989. International Journal of Remote Sensing, v. 12, p.1113-1115. 